BRANDÃO, José Manuel. Paul Deshayes (1796-1875) e a Comissão Geológica do Reino: uma colaboração com o Estado português. História, Ciências, Saúde Manguinhos, Rio de Janeiro, v.20, n.3, jul.-set. 2013, p.865-883.

\section{Paul Deshayes} (1796-1875) e a Comissão Geológica do Reino: uma colaboração com o Estado português

Paul Deshayes (1796-1875) and the Geological Commission of the Kingdom: a collaboration with the Portuguese state

\author{
José Manuel Brandão \\ Pesquisador do Centro de Estudos de História e \\ Filosofia da Ciência/Universidade de Évora. \\ Largo Marquês do Marialva, 8 \\ 7000-554 - Évora - Portugal \\ josembrandao@gmail.com
}

Recebido para publicação em maio de 2011. Aprovado para publicação em março de 2012.

\section{Resumo}

Carlos Ribeiro, um dos diretores da Comissão Geológica de Portugal, empreendeu em 1858 viagem por vários países da Europa, para adquirir bibliografia, equipamentos e coleções de comparação. Em Paris, conheceu o reputado conquiliologista Paul Deshayes, que lhe franqueou suas coleções pessoais do Terciário francês e o ajudou na classificação de fósseis portugueses. $\mathrm{O}$ trabalho conjunto revela-se na listagem de Ribeiro conservada no arquivo histórico do Laboratório Nacional de Energia e Geologia (Alfragide, Portugal), tendo aquelas classificações servido de base a uma monografia publicada por Pereira da Costa, parceiro de Ribeiro na Comissão Geológica, e à definição da estratigrafia dos depósitos terciários portugueses.

Palavras-chave: Comissão Geológica; Carlos Ribeiro (1813-1882); Paul Deshayes (1796-1875); Terciário; Portugal.

\section{Abstract}

Carlos Ribeiro, one of the directors of the Geological Commission of Portugal, voyaged in 1858 to many countries of Europe to acquire publications, equipment and comparator collections. In Paris he met Paul Deshayes, a well-known conchologist, who gave him access to his personal collections of Tertiary deposits from France and helped him to classify Portuguese fossils. The outcome of the joint work can be seen in the Ribeiro List, which is preserved in the historic archives of the National Energy and Geology Laboratory (Alfragide, Portugal). These classifications served as a basis for a monograph published by Pereira da Costa, Ribeiro's colleague on the Geological Commission, and the definition of the stratigraphy of Portugal's Tertiary deposits.

Keywords: Geological Commission; Carlos Ribeiro (1813-1882); Paul Deshayes (1796-1875); Tertiary; Portugal. 
Ninguém contesta a grande vantagem que pode proporcionar o conhecimento dos fósseis aplicado à história das camadas que os contêm. Recusar o auxílio desta ciência à geognosia tal como a hoje a entendemos, seria querer, por exemplo, contar a história dos povos antigos sem as suas medalhas e sem os seus monumentos. ${ }^{1}$

Deshayes (1831, p.1)

Durante o século XIX, intensificou-se a circulação de naturalistas e acadêmicos entre as instituições científicas europeias, tendo em vista o intercâmbio de experiências e conhecimentos. Dessas viagens de estudo resultou, entre outros benefícios, transferência de conhecimento que se foi refletindo na implementação de novas metodologias de trabalho e no recurso a novas fontes documentais. Essa prática foi também adotada por diversos cientistas portugueses, entre os quais os membros da Comissão Geológica do Reino criada em 1857, serviço oficial encarregado de proceder ao reconhecimento geognóstico do país e elaborar a respectiva cartografia em diferentes escalas, instrumento fundamental para o conhecimento dos recursos do subsolo, indispensáveis ao desenvolvimento do país. Tal desiderato implicava dotar o recém-criado serviço do Estado dos meios necessários, nomeadamente uma biblioteca especializada e coleções de comparação fiáveis, uma vez que os trabalhos de separação e datação das formações que constituíam a ossatura geológica do território a cartografar assentavam, em boa parte, na determinação dos fósseis nelas contidos.

Por outro lado, essa tarefa complexa confiada à Comissão, constituída por apenas três técnicos apetrechados para os trabalhos de geologia, coadjuvados por auxiliares, apontava, estrategicamente, para a necessidade de cooperação com outras personalidades da ciência, especialistas nos diferentes domínios da mineralogia, da geologia e da paleontologia, que dificilmente poderiam encontrar-se dentro das fronteiras nacionais. Fica assim desenhado o quadro que levou o engenheiro Carlos Ribeiro (1813-1882), um dos primeiros diretores da Comissão, a diversos países da Europa ocidental e central, num périplo de vários meses durante os quais teve oportunidade de visitar diversas instituições e contactar, em seus próprios locais de trabalho, personalidades das ciências geológicas europeias, de que se destacam, entre outros, Élie de Beaumont, Valenciennes e Deshayes na França, Hörnes e Haidinger em Viena, Barrande em Praga e, no regresso por Madri, Casiano de Prado e Vilanova. ${ }^{2}$

Durante a estada em Paris, Ribeiro teve oportunidade de privar e trabalhar, em particular, com Gérard Paul Deshayes (1796-1875), cuja colaboração se revelou preciosa para a determinação de algumas faunas fósseis portuguesas essenciais para o estabelecimento da estratigrafia do Terciário da região da Grande Lisboa, assunto que se desenvolve no presente artigo.

\section{Motivações da viagem}

Pode dizer-se que os estudos geológicos sistemáticos do território português se iniciaram na sequência das reformas do governo liberal em 1852, que determinou a criação do Ministério das Obras Públicas, Comércio e Indústria, no seio do qual foi criada uma repartição 
de minas. A chefia desse novo serviço oficial foi confiada a Carlos Ribeiro que, a partir de então, desenvolveu importante atividade de estudo das potencialidades minerais do país, publicando diversas 'memórias' editadas entre 1853 e 1858. Contudo, o país continuava a carecer de estudo geológico global e da respectiva carta, missão que havia sido confiada a uma comissão especializada criada em 1848 na Academia Real das Ciências de Lisboa, chefiada pelo engenheiro francês Charles Bonnet (1816-1867), que se encontrava em Portugal trabalhando por conta de concessionários privados.

Essa comissão foi oficialmente extinta em 1855, tendo suas funções sido cometidas à (nova) Comissão Geológica criada por diploma régio de 1852, a qual, por dificuldades de vária ordem, só começou a funcionar em 1857, tendo como diretores Carlos Ribeiro e o acadêmico Francisco Pereira da Costa (1809-1889), graduado em medicina e lente de mineralogia e geologia na Escola Politécnica de Lisboa.

Ao entrar em atividade, provisoriamente instalada em casa de Pereira da Costa, a Comissão não dispunha das condições necessárias à prossecução de sua principal finalidade, situação que se prolongou ainda por um largo par de anos. Faltavam-lhe espaços adequados à disposição dos materiais resultantes dos trabalhos de campo, uma 'livraria' especializada e coleções de comparação de fósseis, minerais e rochas, adequadas aos trabalhos em curso.

A Comissão Geológica tem lutado com todos os embaraços inerentes a um estabelecimento científico nascente. Sem meios para a aquisição de livros e coleções no estrangeiro, teve de esperar que suas próprias economias se elevassem a uma soma suficiente para fazer gradualmente essas compras. Por mais de um ano não possuiu edifício próprio em que pudesse dispor os objetos que ia sucessivamente coligindo (Ribeiro, Costa, 1865, p.6-7).

Tendo em vista a classificação, por comparação, das coleções entretanto organizadas na sequência dos trabalhos de campo, e a aquisição dos materiais que careciam à Comissão, foi Carlos Ribeiro indigitado para uma viagem pela Europa, decorrida entre julho e dezembro de $1858^{3}$, que permitisse estabelecer, simultaneamente, rede de contatos com personalidades e organizações científicas congêneres para garantir, a prazo, a permuta de conhecimentos e a internacionalização da geologia portuguesa.

\section{Fósseis na bagagem}

Por razões de ordem prática a Comissão começou a desenvolver os primeiros trabalhos de levantamento geológico de que o país tanto carecia, sobre as formações secundárias e terciárias dos arredores de Lisboa e da península de Setúbal, cujo esboço havia sido publicado em 1841 por Daniel Sharpe (1806-1856), membro da Royal Society, que viveu algum tempo em Portugal - onde mantinha negócios - e com quem Ribeiro privou e manteve correspondência até o trágico acidente que vitimou o inglês. Nesse trabalho, intitulado On the geology of the neighbourhood of Lisbon, Sharpe referia com algum pormenor as formações terciárias de Lisboa e da margem sul do Tejo, baseando-se não apenas em suas observações de campo, mas também nos elementos fornecidos pela coleção de fósseis que seu conterrâneo James Smith (1782-1867) formara quando de sua estada em Lisboa, à qual tivera acesso. Smith (Jan. 1847, p.410) condensou o estudo dessa amostragem num artigo publicado 
pela Geological Society de Londres, em que descreve longa lista de "fósseis testáceos" cuja determinação fora supervisionada por George Sowerby (1788-1854), os quais lhe tinham permitido concluir que esses depósitos correspondiam "à divisão II do miocênico de Lyell, e eram paralelos aos depósitos terciários das bacias de Bordeaux e Dax". Todavia, referia ainda, encontrar algumas diferenças entre as formas portuguesas e a coleção de Bordeaux, que talvez pudessem explicar-se pela "distância entre as duas bacias".

Das três unidades identificadas por Sharpe (1841), de cima para baixo Upper Tertiary Sand, Almada Beds e Lower Tertiary Conglomerate, a segunda, Camadas de Almada, na qual tinham sido também colhidos os fósseis de J. Smith, constituía, em sua opinião, a mais interessante formação do Terciário português, em consequência da diversidade das rochas presentes e da abundância de restos orgânicos (p.109). É precisamente essa mesma grande unidade miocênica que capta também a atenção dos membros da Comissão Geológica, em particular de Ribeiro, que nela realiza diversos 'cortes' e colheitas.

Dada a carência de elementos de comparação para o estudo cabal dos materiais recolhidos durante os trabalhos de campo que empreendera, Ribeiro fez incluir na bagagem uma coleção de fósseis recolhidos na bacia terciária do Tejo e no sul do país, a fim de os classificar e validar, por comparação com as coleções estrangeiras depositadas nos museus que tinha programado visitar. Esse trabalho constituía, em seu entendimento, "uma necessidade imperiosa da comissão" (Ribeiro, 1859, p.151), conquanto os fósseis eram, como é sabido, ferramentas fundamentais em estratigrafia, e só por sua determinação seria possível sequenciar e cartografar as unidades geológicas presentes.

A França, como se depreende do relatório entregue à tutela depois do regresso a Lisboa (1859), era o país em que aquele membro diretor da Comissão Geológica depusera maiores expectativas consequência do fato, dizia, de haver ali muitos geólogos e engenheiros de minas a "trabalhar e publicar a respeito dos fósseis e da constituição geológica do império" (Ribeiro, 1859, p.151).

\section{O trabalho em Paris}

O estudo das coleções que levou de Lisboa começou na Escola de Minas de Paris, na qual pontificava desde 1835 Élie de Beaumont, a quem foi apresentado através de recomendação do embaixador português naquela cidade (Leitão, 2001, p.294). Nessa reputada escola estavam depositadas as coleções da carta geológica da França, trabalho que Beaumont iniciara em 1825 em colaboração com Pierre Dufrenoy (1792-1857) ${ }^{4}$, e foi continuando ao longo da sua carreira.

Todavia, conquanto Ribeiro (1859, p.152) concluísse que os fósseis das bacias terciárias da França que consultara constituíam "excelente e mimosa coleção de ensino", sua organização, "coordenada zoologicamente com os seres fósseis das diferentes idades da terra, onde se encontram as espécies mais características e frequentes", revelou-se pouco adequada para servir ao estudo comparativo de seus exemplares.

À conclusão semelhante chegou também, na sequência da consulta das coleções do Jardin des Plantes, disponibilizadas por Achilles Valenciennes (1794-1865), professor de conquiliologia no Muséum d'Histoire Naturelle. Dessa, dizia ter tirado muito proveito para sua instrução particular, mas, quanto à verificação das espécies portuguesas, não tinha podido chegar a 
um resultado concludente. Foi então que decidiu procurar Deshayes, cuja obra e reputação certamente já conheceria, e a quem reputava de "especialista mais eminente na conquiliologia fóssil dos terrenos terciários", a quem se apresentou "sem outra recomendação mais do que o [seu] bilhete de visita" (Ribeiro, 1859, p.152) e um interesse comum: os fósseis do Terciário.

\section{Perfil abreviado do colaborador benévolo}

Gérard Paul Deshayes (Figura 1), um dos fundadores da Société Géologique de France, fixou-se em Paris em 1820, abandonando a carreira médica para se dedicar à história natural, em particular ao estudo da conquiliologia. Enquanto assistia no Muséum às aulas de Messers, Beaumont, D'Archiac, Verneuil e Prévost, entre outros, começou a dar cursos privados de geologia, realizando algumas saídas de campo.

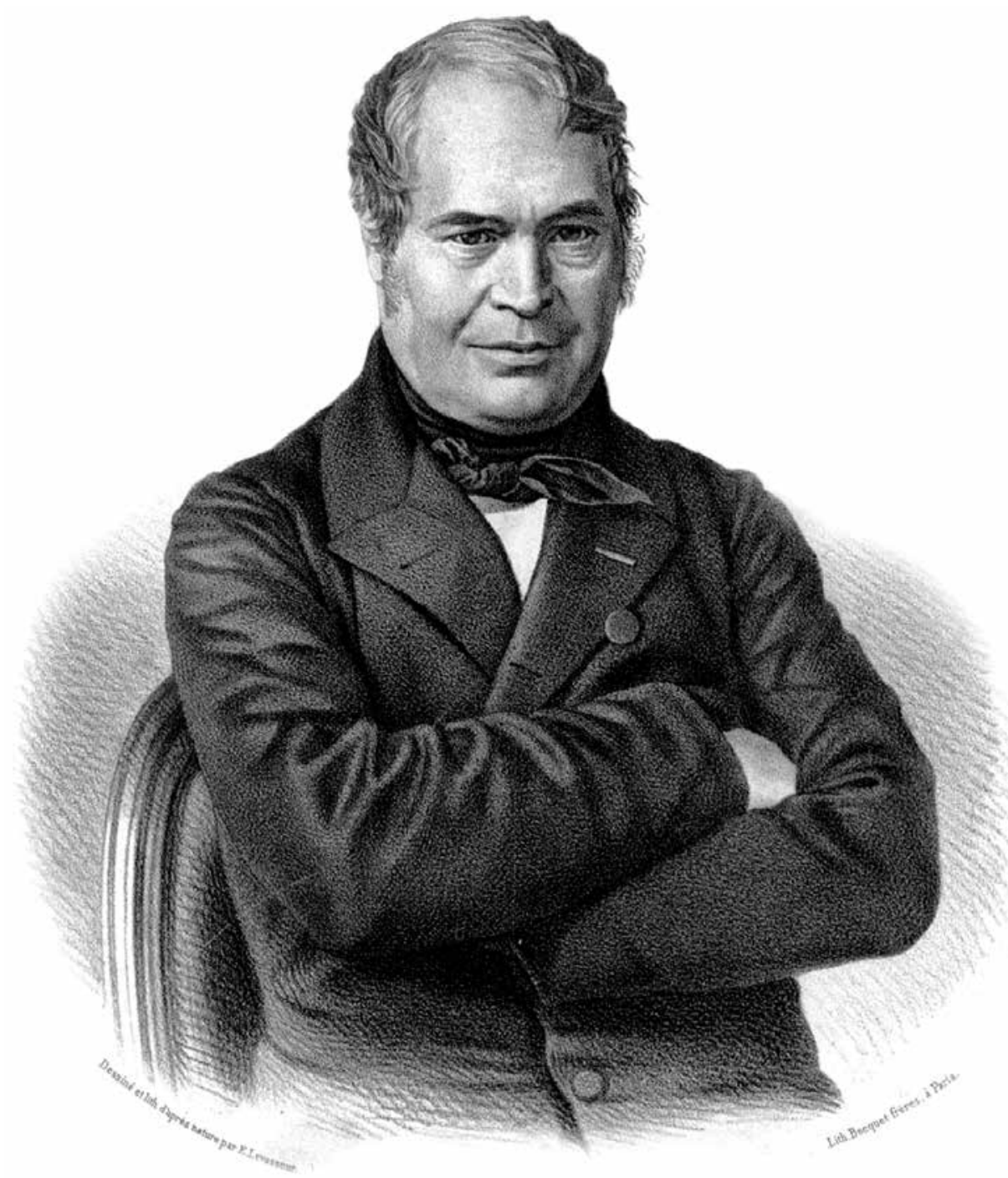

Figura 1: Gérard Paul Deshayes (1796-1875) (Arquivo do Muséum National d'Histoire Naturelle, Paris; cortesia de Jean Gaudant) 
Em 1823 publicou a primeira memória geológica sobre os fósseis do Terciário da região de Paris e, em 1824, com seus próprios recursos "que não eram consideráveis" como referem Crosse e Fischer (1876, p.123), começou a edição da Description des coquilles fossiles des environs de Paris (1824-1837), na qual, além da descrição dos materiais recolhidos nas jazidas que descobrira, elencou muitos exemplares pertencentes a outras coleções.

Propus-me alcançar dois objetivos: o primeiro e principal dar a conhecer, com descrições e figuras todas as conchas fósseis que foram encontradas até agora nos arredores de Paris, reunindo numa só coletânea todos os materiais dispersos pelas memórias de vários cientistas; e reunir não só tudo o que as minhas viagens e pesquisa me possibilitaram recolher, mas ainda tudo o que podem oferecer de novo as coleções de homens de ciência como Defrance, Brongniart, Roissy, Duclos, Ménard de Groye etc. que com uma bondade e complacência particulares me permitiram consultar materiais preciosos, contribuindo desta forma para o sucesso dos meus propósitos (Deshayes, 1824-1837, v.1, p.1).

Em 1830, baseando-se nas percentagens de espécies fósseis idênticas às faunas vivas e, jogando, em contraponto, com as percentagens de espécies extintas presentes nas formações terciárias estudadas, propôs um modelo de seriação das camadas em três grandes conjuntos, definidos pelo aumento do número de espécies idênticas, cuja flutuação relacionava com variações de temperatura durante o Terciário.

Impressionado pelos resultados obtidos por Deshayes no estudo comparativo dos moluscos fósseis de diversas bacias terciárias, Charles Lyell (1797-1875) encarregou-o de condensar sob a forma de quadro "todas as conchas que ele sabia apresentarem-se ambos em qualquer formação terciária e no estado vivo, a fim de que se pudesse estabelecer o número de espécies fósseis idênticas com as espécies recentes, que caracterizassem os grupos sucessivos" (Lyell, 1856, p.186). Estes quadros, que o ajudaram a consolidar o modelo de divisão do Terciário (Eocênico, Miocênico e Pliocênico), foram incluídos no final de Principles of geology editado em 1933 (Zittel, 1901, p.431). ${ }^{5}$

Deshayes assinou várias obras, sendo reconhecidamente mais marcante Description des animaux sans vertèbres du bassin de Paris (1860-1866), para a qual se valeu também de diversas coleções constituídas localmente por outros estudiosos e paleontólogos amadores.

Dos sistemas conquiliológicos estabelecidos, seguiu de perto a Philosophia zoológica, de Lamarck, a quem chamava o Lineu francês (Deshayes, 1839-1853, v.3, p.27), organizando os moluscos em 'famílias naturais', modelo que preferiu ao de Cuvier.

As contingências da vida forçaram-no a vender suas coleções, compradas pelo Estado em 1868 e depositadas na Escola de Minas, passando posteriormente para a Universidade de Lyon onde atualmente se encontram. Em 1869 foi nomeado professor de conquiliologia no Muséum d'Histoire Naturelle de Paris, posição em tempos ocupada por Lamarck, tendo ali contribuído para o crescimento das coleções malacológicas (Evans, 1876, p.81).

\section{O trabalho com Deshayes}

Tal como refere Vanda Leitão (2001, p.296), o acolhimento que Deshayes dispensou a Carlos Ribeiro não poderia ter sido melhor, disponibilizando-se de imediato a colaborar e destinando um ou dois dias da semana para verificar e corrigir as espécies de univalves e de bivalves fósseis portugueses e separar as espécies que, eventualmente, se configurassem novas. 
Além disso franqueou-lhe a biblioteca pessoal, o que aliás já era hábito fazer com outros homens de ciência que o visitavam, facilitando-lhe o acesso a suas coleções, que continham a maior parte das espécies que recolhera em vários pontos da França e publicara.

Acrescente-se que as faunas de moluscos vivos de Portugal não eram inteiramente desconhecidas desse homem de ciência pois já anteriormente tinha sido consultado pelos naturalistas franceses Arthur Morelet (1809-1892) e Henri Drouet (1829-1900), quando dos estudos que, a serviço da coroa portuguesa, eles realizaram sobre as faunas testáceas terrestres e fluviais. Além disso seus préstimos foram também solicitados pelo zoólogo José Vicente Barbosa do Bocage (1823-1907), lente da Escola Politécnica e diretor do respectivo Museu Zoológico, para classificação de "conchas terrestres e fluviais" do continente e da ilha da Madeira (Ribeiro, 10 fev. 1859).

As coleções que conservava em sua casa de Paris, particularmente ricas de "acéfalos vivos"6 e moluscos terciários de toda a França, eram como "uma biblioteca sempre aberta aos estudiosos" (Crosse, Fischer, 1876, p.126). Ribeiro (1859, p.152-153), aliás, não lhe poupou elogios reputando-a como "a mais completa e a mais cientificamente ordenada de todas quantas vi[ra] na França, Alemanha e Itália". Tal admiração decorreria certamente do padrão de organização seguido, revelador da preocupação de seu autor em dar à conquiliologia aplicação prática, de carácter estratigráfico e evolutivo.

Deshayes reúne zoologicamente em cada gênero, todas as espécies e variedades conhecidas, quaisquer que sejam as formações terciárias a que pertençam; e dispondo depois as espécies de cada gênero na ordem geológica ou cronológica, coloca à testa de cada gênero a espécie viva que lhe serviu de tipo, adicionando depois à coleção de cada gênero uma ou mais espécies das épocas anteriores ao período terciário; e, escolhidas segundo o maior número de afinidades com a espécie tipo, forma um quadro onde se vê imediatamente não só a época em que cada gênero apareceu ... mas o desenvolvimento e modificações por que passaram, as espécies que se perderam, as novas que apareceram com as vicissitudes por que a terra passou ... e finalmente a forma mais típica por que é representado na natureza viva (Ribeiro, 1859, p.152).

A única memória material do trabalho realizado em casa de Deshayes é a lista em que se enumeram as peças classificadas sob supervisão do naturalista francês, conservada no Arquivo Histórico Geológico e Mineiro (AHGM) do Laboratório Nacional de Energia e Geologia $(\mathrm{LNEG})^{7}$, datada de 4 de setembro de 1858, poucos dias antes de Ribeiro retomar o périplo europeu, rumo à Alemanha (Figura 2).

Além da denominação específica e autoria de cada um dos exemplares, nessa lista indicamse também o lugar de colheita, um número que admitimos possa corresponder à marcação original de campo e, pontualmente, algumas anotações referentes ao estado de preservação, a semelhanças entre exemplares ou à verificação do exemplar por Deshayes. Não se registraram, por conseguinte, detalhes sobre a estratigrafia das formações que, afinal, só seria concluída alguns anos depois, tendo por base os estudos paleontológicos iniciados por Ribeiro. ${ }^{8}$

Nessa lista, com 614 números, são referidas mais de quatrocentas espécies de moluscos fósseis, quase todas de gastrópodes, assinalando-se 44 exemplares como correspondendo a espécies novas que Deshayes se escusou a "descrever e nomear" (Ribeiro, 1859, p.153), reservando essa honrosa tarefa para os membros da Comissão Geológica (Quadro 1). ${ }^{9}$ 


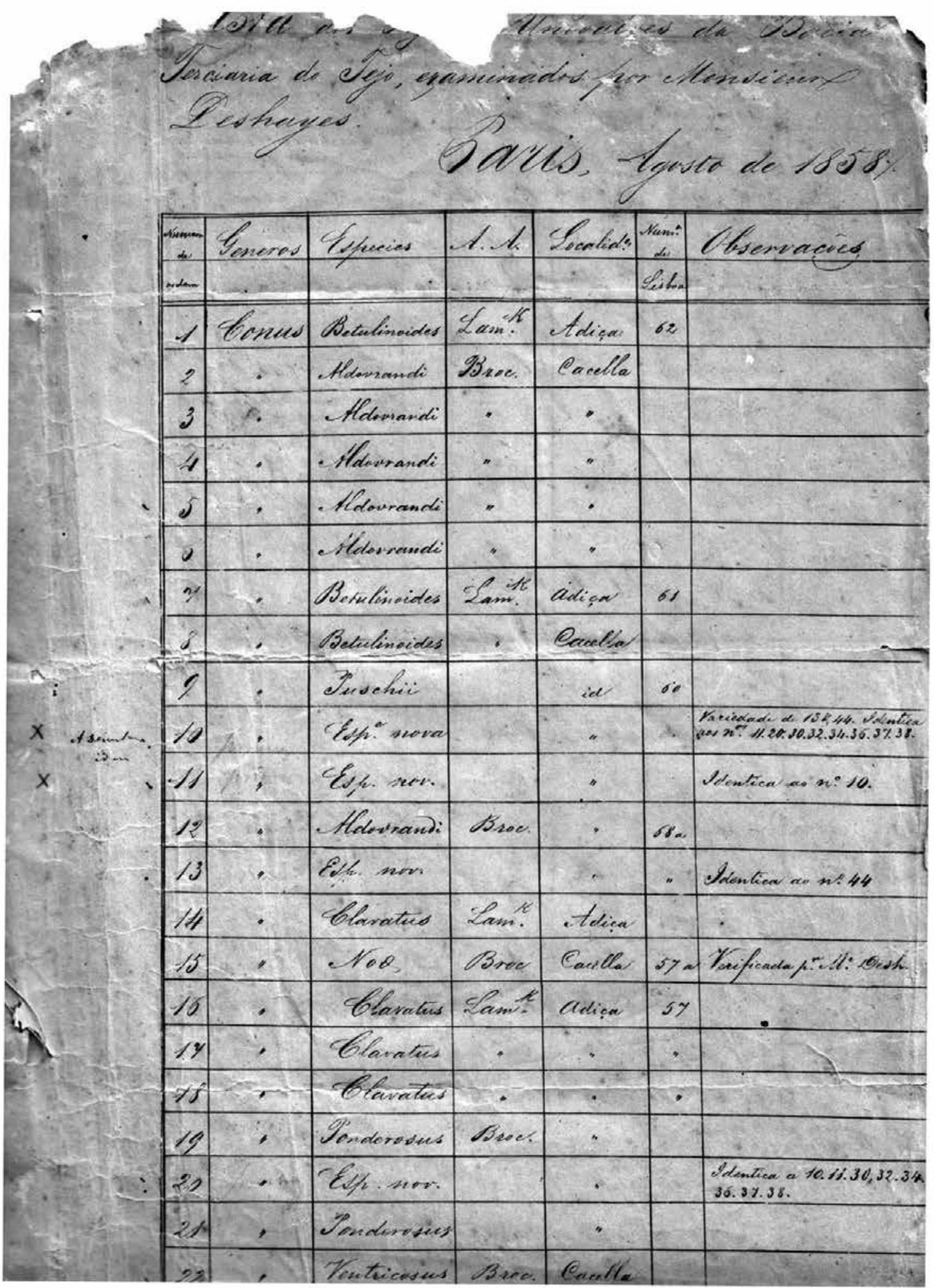

Figura 2: Frontispício da listagem manuscrita de Carlos Ribeiro, relativa aos fósseis examinados por Deshayes (4 set. 1858) (Arquivo Histórico Geológico e Mineiro do Laboratório Nacional de Energia e Geologia, Portugal) 
Quadro 1: Súmula da listagem de Carlos Ribeiro e áreas de amostragem em Portugal

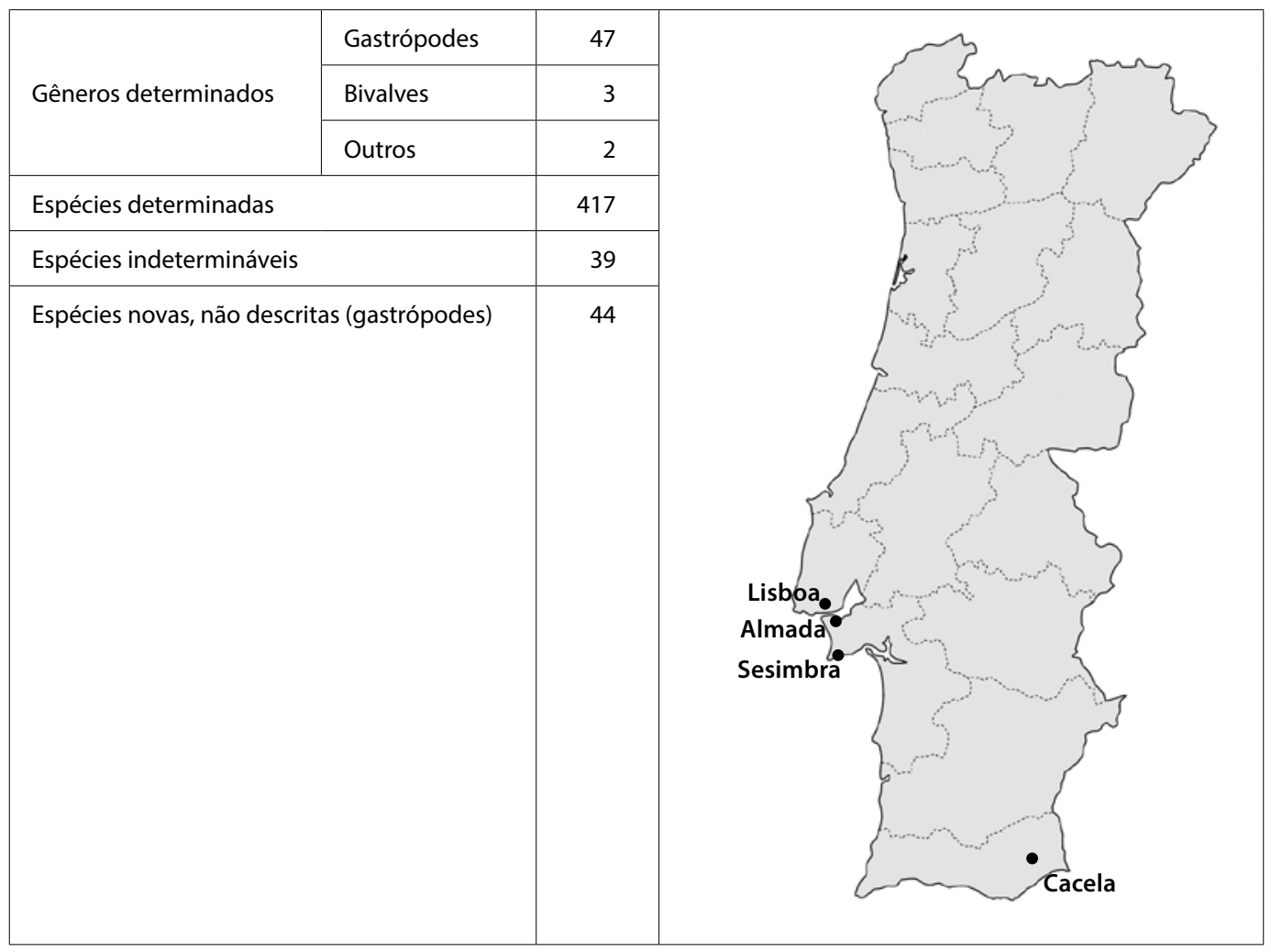

Fonte: Organizado pelo autor a partir da listagem manuscrita de Carlos Ribeiro. Indicam-se no mapa as áreas de proveniência das peças estudadas pelos dois cientistas.

A maior parte dos exemplares estudados resultou das colheitas realizadas em diversos pontos da cidade de Lisboa e nas formações da margem esquerda do Tejo, entre Almada e Sesimbra ${ }^{10}$, áreas em que o Miocênico marinho está mais bem representado; registre-se, contudo, a presença de vários exemplares provenientes da importante jazida de Cacela no Algarve $^{11}$, que tanto Ribeiro como Pereira da Costa exploraram, embora sem grande pormenor.

Em Lisboa e na outra banda do Tejo até Setubal e o cabo Espichel é que o miocênico marinho se apresenta com mais desenvolvimento; com efeito esse depósito forma toda a escarpa do Tejo em frente de Lisboa, dobra a ponta da Trafaria e constitui quase toda a escarpa marítima até perto do cabo Espichel. No litoral do Algarve também se encontram camadas marinhas miocênicas entre Lagos e Faro e entre Tavira e Cacela, formando a escarpa marítima nesses lugares (Ribeiro, Costa, 1865, p.12).

Como, por falta de elementos, se desconhece a constituição da coleção preparada por Ribeiro na partida de Lisboa, torna-se difícil aferir o sucesso do trabalho realizado em casa do naturalista parisiense; no entanto pode-se supor que os resultados obtidos foram, decerto, mais relevantes do que os obtidos pela consulta das coleções do Jardin des Plantes, que terá correspondido a um décimo dos itens, como Ribeiro revelou a Valenciennes na carta referida por Vanda Leitão (2001, p.294). 
O trabalho conjunto dos dois sábios ter-se-á prolongado porventura mais tempo do que o inicialmente previsto por Ribeiro, pelo que Deshayes se disponibilizou para receber o resto da coleção e continuar o trabalho, enquanto o primeiro retomaria sua viagem.

\section{Novas coleções para a Comissão Geológica}

Fascinado que estava pela qualidade e diversidade de formas do Terciário da França, em grande parte descritas por seu anfitrião, Ribeiro não abandonou definitivamente Paris sem encomendar uma coleção de fósseis terciários de Bordeaux e Dax ao reputado marchand Louis Sæmann (1821-1866), a quem a Comissão Geológica viria a fazer posteriormente outras aquisições (Brandão, 2010), bem como uma coleção de "todas as espécies fósseis da bacia terciária de Paris" para ser vista, nomeada e coordenada pelo próprio M. Deshayes (Ribeiro, 1859 , p.156). Esta última coleção deveria vir a ter, quando completa, entre 1.400 e 1.800 espécies, correspondendo-lhe dois a três mil exemplares. ${ }^{12}$

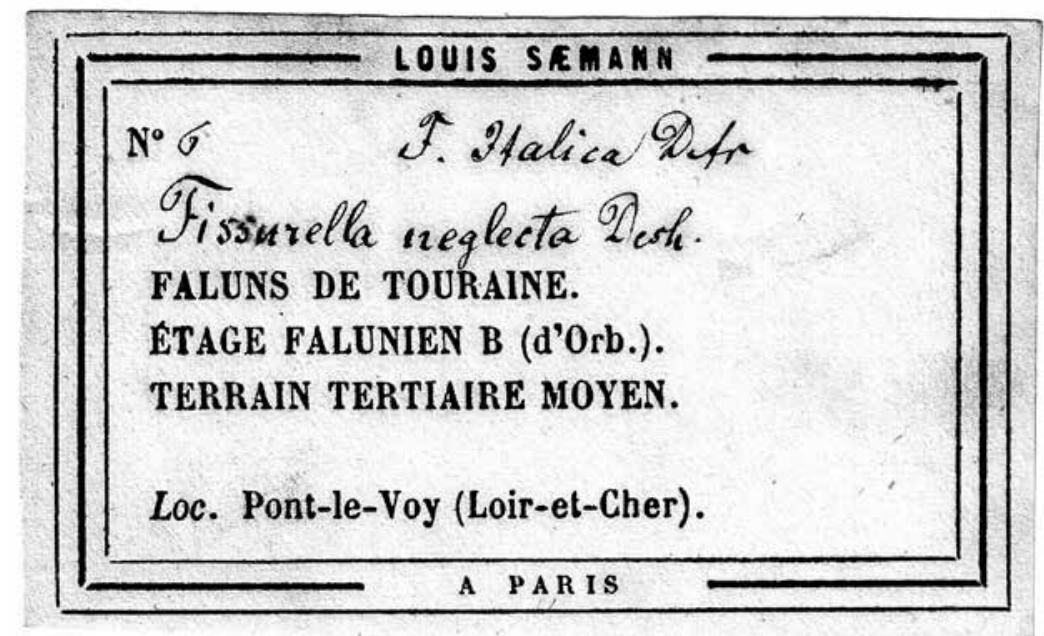

Figura 3a: Etiqueta certamente correspondente às peças encomendadas por Carlos Ribeiro na década de 1860 (Arquivo Histórico Geológico e Mineiro do Laboratório Nacional de Energia e Geologia, Portugal)

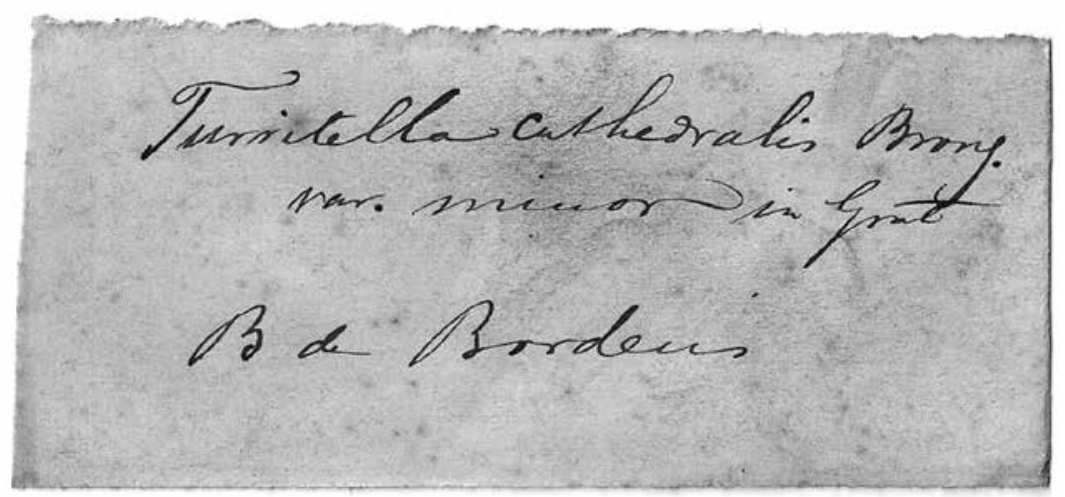

Figura 3b: Corresponde, muito possivelmente, à transcrição do original enviado com as colheitas pessoais de Louis Sæmann, em setembro e outubro de 1858, determinadas segundo J.P. Grateloup (Museu Geológico do Laboratório Nacional de Energia e Geologia, Portugal; peça n.18734) 
Além dos conhecimentos de sistemática, Ribeiro terá adquirido também com o naturalista parisiense algumas novas metodologias de trabalho. Disso é testemunha a carta que no ano seguinte dirigiu ao famoso livreiro J.-B. Baillière (1797-1885), de Paris, a quem a Comissão entregou desde 1858 boa parte das aquisições para sua 'livraria', para que fosse, de sua parte, a casa de Deshayes na Place Royal, 18, $1^{\mathrm{er}}$, fazer um croqui do aparelho que aquele sábio usava, que se compunha de um sistema de alavancas com uma lupa superposta.

Tratava-se, obviamente, de uma câmara clara, que o naturalista usaria para estudar os caracteres das conchas, ficando assim com as mãos livres para concomitantemente os poder desenhar. Nessa carta Ribeiro (8 mar. 1859) pedia também para fazer um clinômetro "para medir o ângulo das conchas univalves segundo as indicações de Deshayes".

Durante a viagem, Ribeiro adquiriu diversas obras para a Comissão, algumas delas por sugestão de Deshayes, durante sua estada em Paris. É muito provável que tenha sido nessa ocasião a compra dos principais títulos assinados pelo conquiliologista francês, editados até aquela data, a que se vieram somar, posteriormente, as demais publicações, as quais terão tido imediata aplicação nos trabalhos de catalogação que Pereira da Costa empreendera ${ }^{13}$ (Quadro 2).

Quadro 2: Obras de Paul Deshayes incorporadas à biblioteca da Comissão Geológica

\begin{tabular}{|c|c|c|}
\hline N. & Título & Data \\
\hline 7212 & $\begin{array}{l}\text { Histoire naturelle générale et particulière des mollusques terrestres et fluviatiles...; ; v., } 2 \text { atlas. } \\
\text { Colaboração com J.-B. de Férussac }\end{array}$ & $1820-1851$ \\
\hline 664 & $\begin{array}{l}\text { Mémoire géologique sur les fossiles de Valmondois, principalement sur les coquilles perforantes } \\
\text { découvertes dans le grés marin inférieur }\end{array}$ & 1822 \\
\hline 662 & Description des coquilles fossiles des environs de Paris; $2 \mathrm{v}$., atlas & $1824-1837$ \\
\hline 663 & Description de coquilles caractéristiques des terrains & 1831 \\
\hline 665 & $\begin{array}{l}\text { Observations sur l'estimation de la température des périodes tertiaires en Europe fondée sur la } \\
\text { considération des coquilles fossiles }\end{array}$ & 1836 \\
\hline 6860 & $\begin{array}{l}\text { Traité élémentaire de conchyliologie: avec les applications de cette science à la géologie; 3v.,1 } \\
\text { atlas }\end{array}$ & $1839-1853$ \\
\hline 3587 & $\begin{array}{l}\text { "Mollusques". Série de artigos no Magasin de zoologie, d'anatomie comparée et de } \\
\text { paléontologie }\end{array}$ & $1840-1843$ \\
\hline 661 & Description des animaux sans vertèbres découverts dans le bassin de Paris...; 3v., 2 atlas & $1860-1866$ \\
\hline 666 & Distribution des mollusques acéphales dans le bassin tertiaire de Paris & 1861 \\
\hline 3469 & Conchyliologie de lîle de la Réunion (Bourbon) & 1863 \\
\hline
\end{tabular}

Fonte: Organizado pelo autor a partir do índice geral do acervo da biblioteca do Laboratório Nacional de Energia e Geologia, Portugal.

\section{Reconhecimento e distinção real}

De regresso ao trabalho em Lisboa, Ribeiro (10 fev. 1859) não se furtou a generoso agradecimento a Deshayes que rematou dizendo "Nunca vou esquecer as suas conversas instrutivas e encantadoras, nem a bondade e gentileza com que o senhor sempre me recebeu em sua casa". 
Também Pereira da Costa, em carta dirigida à tutela, enalteceu o reconhecimento pelo desinteressado contributo do francês, enfatizando: "Os serviços prestados por este sábio a nossa Comissão, sendo importantes pelos resultados que nos proporcionam, tornam-se de um valor mais subido se se atender a que são prestados por um homem que não tem patrimônio nem emprego público de que perceba ordenado e que vive unicamente do produto de seu trabalho, para quem, por conseguinte, o tempo é dinheiro, e o dinheiro do pão quotidiano" (Costa, Ribeiro, out. [1859?] $)^{14}$, acrescentando que se lhe devia também uma parte das relações que a Comissão tinha estabelecido na Alemanha e na Itália, designadamente o relacionamento com Wilhelm Haidinger (1795-1871) e, sobretudo, Moriz Hörnes (1815-1868) do Gabinete de Mineralogia e Geologia de Viena, também visitados por Ribeiro, cuja colaboração viria a ser determinante no estudo das faunas fósseis portuguesas.

À relevância da colaboração Costa $(1859$, p.149) também não se furtou a reconhecer a elevada craveira internacional do naturalista, apontando, simultaneamente, sua modéstia científica:

Em Paris é o senhor Deshayes consultado de todas as partes para autenticar com o seu importante voto a determinação das espécies de moluscos das diversas bacias terciárias; mas o senhor Deshayes, com mais de quarenta anos de trabalhos distintos na ciência, não se atreve a nomear um dente, um equinoderme, ou um polipeiro dos encontrados nos mesmos depósitos terciários, de onde são os moluscos que com a melhor vontade se presta a classificar ... e leva sua benevolência a ponto de ele mesmo pedir para os países estranhos [estrangeiros] a algum sábio especialista que se encarregue da determinação das espécies em que não ousou tocar por não pertencerem à especialidade a que se tem dedicado.

Entre os fósseis levados por Ribeiro, além dos moluscos, certamente o grupo majoritário, haveria também alguns zoófitos, equinodermes e restos de vertebrados marinhos, sobretudo peixes. Os equinodermes foram enviados ao cuidado de Hardouin Michelin (1786-1867), conselheiro do Tribunal de Contas em Paris, "que tinha a melhor coleção que há na França", enquanto os restos de vertebrados foram mostrados a Paul Gervais (1816-1879), paleontólogo e professor na universidade de Montpellier (Ribeiro, 1859, p.153, 156).

O reconhecimento dos membros da Comissão foi, porém, mais longe com a proposta de nomeação de Deshayes para a Academia Real das Ciências de Lisboa, que veio a se concretizar em 24 de março de 1859 com sua eleição como sócio correspondente, e o pedido, através da tutela, ao rei dom Pedro V, de atribuição de distinção honorífica. ${ }^{15}$ Entre outras razões, argumentavam que os serviços que aquele oferecera "nem se poderiam comprar por dinheiro, nem poderiam obter-se de nenhum outro sábio porque nenhum há tão habilitado como Deshayes no estudo dos fósseis dos terrenos terciários dos quais talvez metade das espécies descritas lhe pertençam" (Costa, [1859?]).

Concordando com o pedido, o rei atribuiu-lhe a Comenda da Ordem de Cristo, distinção real concedida por destacados serviços prestados ao país, a que Deshayes (27 out. 1859) reagiu confidenciando a Ribeiro: "Estou extremamente lisonjeado por esta alta distinção que não esperava; no entanto, o senhor conhece a minha filosofia, e eu continuo a minha vida tão modesta como antes". 


\section{Continuação do trabalho com as faunas terciárias}

Ribeiro e Pereira da Costa partilhavam as tarefas científicas da Comissão ocupando-se o primeiro principalmente dos trabalhos de campo e o segundo, dos estudos complementares de gabinete, dada a sua anterior experiência com a classificação das coleções da Academia Real das Ciências, a que dedicara muito do seu trabalho. Desta forma, Costa (16 abr. 1859) chamou a si o estudo detalhado destes fósseis, tendo em vista sua futura publicação, como confidenciaria a Casiano de Prado: "Tenciono dar previamente um catálogo circunstanciado das espécies do indicado depósito terciário, acompanhado da descrição e figuras daquelas que foram separadas por M. Deshayes como espécies ainda não descritas: para essa publicação estão já a fazer-se os desenhos que devem acompanhar".

Entretanto, a insuficiência de cartografia de base geográfica, tarefa para a qual Ribeiro fora solicitado, bem como a diversidade de assuntos sobre os quais a Comissão Geológica era chamada a pronunciar-se, explicará, certamente, o relativo afastamento de Ribeiro desse assunto, não obstante mais algumas recolhas no Algarve e o incentivo do francês ao prosseguimento dos trabalhos sobre as faunas do Terciário português. Enquanto reiterava sua disponibilidade para rever ou classificar as espécies que pudessem levantar dúvidas, Deshayes, aliás, não escondia o próprio interesse nessas investigações, sobretudo quanto ao conhecimento da importância das condições climáticas enquanto fator determinante da diversidade biológica. ${ }^{16}$

O vosso país ocupa a ponta mais meridional da Europa. O terreno Miocênico estende-se, como sabe, por quase toda a Europa até à Polônia; será por isso muito interessante comparar as regiões sul e norte da mesma época geológica para descobrir as influências climáticas e com que força elas atuaram... Para responder a esta questão, é preciso comparar a maior quantidade possível de espécies, porque a influência do clima faz-se sentir tanto sobre o seu número como na variedade! Portanto, nada deve ser negligenciado e as pequenas espécies devem ser procuradas com tanto zelo, como as grandes (Deshayes, 27 out. 1859). ${ }^{17}$

Nessa troca de cartas com Deshayes, em 1859, Ribeiro referia que na última primavera tinha recolhido no Algarve um grande número de fósseis nas formações do Miocênico e do Pliocênico, e que o número de espécies novas encontradas era já bem maior do que aquele que o francês já tinha visto.

As coleções e o vosso catálogo do Terciário estão cada vez mais completas e as vossas espécies novas são já mais numerosas. Portanto, o livro que pretendem publicar terá para a ciência, um grande interesse. Já os ingleses [Sharpe e Smith] vos 'enterraram' uma parte importante das vossas espécies novas, por isso temendo a possibilidade de um novo roubo do mesmo tipo, a melhor forma de o prevenir é publicarem vocês os materiais que vos pertencem a todos os títulos (Deshayes citado em Costa, 1 dez. 1859).

Pereira da Costa (13 abr. 1860) não enjeitou a oferta de colaboração, para o "catálogo circunstanciado" que preparava e, sem qualquer pejo, referiu que se lhe ofereciam dúvidas em vários exemplares: “Tive muitas dificuldades na determinação, e até mesmo na descrição das espécies que recolhemos: o estado [de preservação] dos exemplares, a falta de livros e coleções [de comparação], e mais ainda os meus insuficientes conhecimentos de Paleontologia são as principais causas destas dificuldades". 
A troca de correspondência regular entre o conquiliologista e os membros da Comissão Geológica parece ter esfriado desde então, o que se depreende tanto da escassez de documentos posteriores a 1859 como de uma carta bastante posterior do francês, em que ele se mostra gentilmente zangado com Ribeiro: "O senhor merece uma grande reprimenda meu caro Ribeiro... mas, passemos uma esponja sobre o silêncio teimoso que manteve comigo e apertemos as mãos amigavelmente" (Deshayes, 31 maio 1863) ${ }^{18}$, para logo em seguida manifestar regozijo pela carta que Ribeiro lhe tinha enviado, confessando ter aguardado com impaciência a chegada da caixa com fósseis que lhe fora mandada, a cuja qualidade não poupou elogios.

Mais três anos decorreriam ainda até a publicação do estudo sobre as faunas terciárias portuguesas assinado por Pereira da Costa, intitulado Moluscos fósseis: gasterópodes dos depósitos terciários de Portugal (1866-1867). A obra em dois fascículos teve por base as coleções da Comissão estudadas com a colaboração de Deshayes e Hörnes, a que Carlos Ribeiro juntou muitos outros exemplares, sobretudo provenientes da jazida de Cacela, cuja determinação terá levado certamente em conta as coleções oportunamente encomendadas na França, nomeadamente de fósseis da bacia de Paris, e que Deshayes se tinha encarregado "de rever e autorizar como típica" (Costa, Ribeiro, out. [1859?]).

O senhor Deshayes fez-nos, há anos o especial favor de passar pela vista uma coleção dos nossos fósseis terciários, menos completa do que aquela que atualmente possuímos; essa coleção foi-nos devolvida com a classificação que esse exame lhe sugeriu para as espécies já conhecidas, e a designação das formas que lhe pareceram que deveriam constituir espécies novas ... O senhor Hörnes enviando-nos a sua classificação de um pequeno número de espécies de gasterópodes do nosso terreno terciário, que a Comissão Geológica de Portugal lhe ofereceu, também tem direito ao testemunho público do nosso reconhecimento (Costa, 1866-1867, p.IX).

Segundo Costa (1866-1867, p.IX), os principais objetivos desse trabalho, destinado sobretudo a quem não tinha possibilidade de consultar as obras estrangeiras em que o assunto estava tratado com maior desenvolvimento, eram os de reunir informação sobre os principais gêneros de moluscos terciários, distinguir os diversos tipos de formas e representálas com a exatidão possível. Contudo, esse autor só publicou os fascículos referentes à fauna de gastrópodes, não tendo editado a descrição dos bivalves, apesar de ter preparado e feito imprimir quase todas as estampas que iriam ilustrar essa parte da obra (Brandão, Almeida, 2005). Só mais tarde, por sugestão do então diretor da Comissão Geológica Nery Delgado (1835-1908), essas estampas foram reunidas e publicadas com legendas elaboradas pelo paleontólogo francês Gustave Dollfus (1850-1931), Berkeley Cotter (1845-1919), membro da Comissão, e Jacinto Pedro Gomes (1844-1916), naturalista do Museu Mineralógico da Escola Politécnica de Lisboa, acompanhadas por um esquema estratigráfico do Terciário da região de Lisboa (Dollfus, Cotter, Gomes, 1903-1904).

Embora Deshayes seja citado com frequência ao longo da obra de Pereira da Costa, nem sempre este esteve de acordo com as determinações do francês, como, aliás, já referira (Costa, 13 abr. 1860) ${ }^{19}$ e se retira de algumas de suas classificações relativas a exemplares atribuídos pelo naturalista a outras espécies. Além disso, das 23 espécies novas que designa em Moluscos fósseis, apenas quatro foram apontadas como tal por Deshayes, sendo 14 delas, 
muito provavelmente, resultantes dessa redenominação ou de colheitas posteriores à estada de Ribeiro em Paris.

As espécies descritas foram organizadas de acordo com o modelo das famílias de Lamarck não porque o autor, em suas próprias palavras, recusasse aceitar os melhoramentos introduzidos na "classificação metódica dos moluscos", mas porque não seria praticável sua aplicação (Costa, 1866-1867, p.VII). O próprio Deshayes, aliás, também seguira, na Description des coquilles fossiles des environs de Paris (1824-1837), aquele sistema que de resto era, de todos os estabelecidos, o mais adotado. Quanto à estrutura, a obra seguiu de perto o modelo usado por Hörnes na descrição dos fósseis da bacia de Viena, trabalho em que se notabilizara e que, na opinião de Pereira da Costa, continha a maior parte das espécies encontradas no Terciário português. ${ }^{20}$

Polarizado com outros assuntos científicos, nomeadamente o estudo das formações terciárias continentais e quaternárias do vale do Tejo, onde fizera importantes descobertas arqueológicas, Ribeiro só viria a noticiar suas observações sobre a estratigrafia do Terciário em 1878, quando do Congresso Internacional de Geologia de Paris. Sublinhe-se que o modelo proposto para a sucessão (Quadro 3) se apoia decididamente nos estudos comparativos com as coleções do Terciário francês que tivera oportunidade de manipular com seu anfitrião parisiense.

Quadro 3: Sucessão do Terciário português

\begin{tabular}{|l|l|}
\hline Miocênico inferior & $\begin{array}{l}\text { I - Formação basáltica } \\
\text { II - Formações sedimentares de água doce com fósseis raros }\end{array}$ \\
\hline $\begin{array}{l}\text { Miocênico médio e } \\
\text { superior }\end{array}$ & $\begin{array}{l}\text { III - Formações marinhas com fósseis análogos aos da bacia mediterrânica e dos arredores } \\
\text { de Viena. Espessura 140m. A maior parte do Miocênico médio e superior apresenta grande } \\
\text { número de fósseis semelhantes aos depósitos marinhos das bacias de Adour e Dax (França) } \\
\text { e a maior parte das espécies da bacia de Viena } \\
\text { IV - Formações de água doce com vertebrados terrestres, invertebrados e plantas fósseis }\end{array}$ \\
\hline Pliocênico & V - Formações arenosas \\
\hline
\end{tabular}

Fonte: Organizado pelo autor a partir de Ribeiro (1880).

O relativo afastamento entre esses homens de ciência não terá, porém, sido óbice a que o conquiliologista francês deixasse passar a oportunidade de elogiar a publicação de Pereira da Costa, a que dedicou uma nota no boletim da Société Géologique de France em 1867 (Deshayes, 1867). Nesse apontamento, depois de referir os anteriores trabalhos de Sharpe e Smith sobre as faunas fósseis portuguesas, Deshayes destacou o sucesso das investigações da Comissão Geológica e o rigor e qualidade das estampas que ilustravam a obra, preparadas com base nos desenhos em 'grandeza natural' de Angelino de Castro, desenhista da Comissão Geológica, também responsável pela preparação das litografias.

Lamentavelmente afigura-se muito difícil a reconstituição das coleções originais de Ribeiro, bem como a de tipos e figurados de Pereira da Costa. Esses exemplares, como as coleções de comparação estrangeiras e praticamente todas as restantes recolhas de campo da Comissão Geológica, foram transferidos, em 1868, para a seção mineralógica do Museu Nacional sediado na antiga Escola Politécnica, onde acabaram por diluir-se nas sucessivas reorganizações das coleções gerais de paleontologia e estratigrafia. ${ }^{21} \mathrm{~A}$ essa situação somaram-se os graves danos 


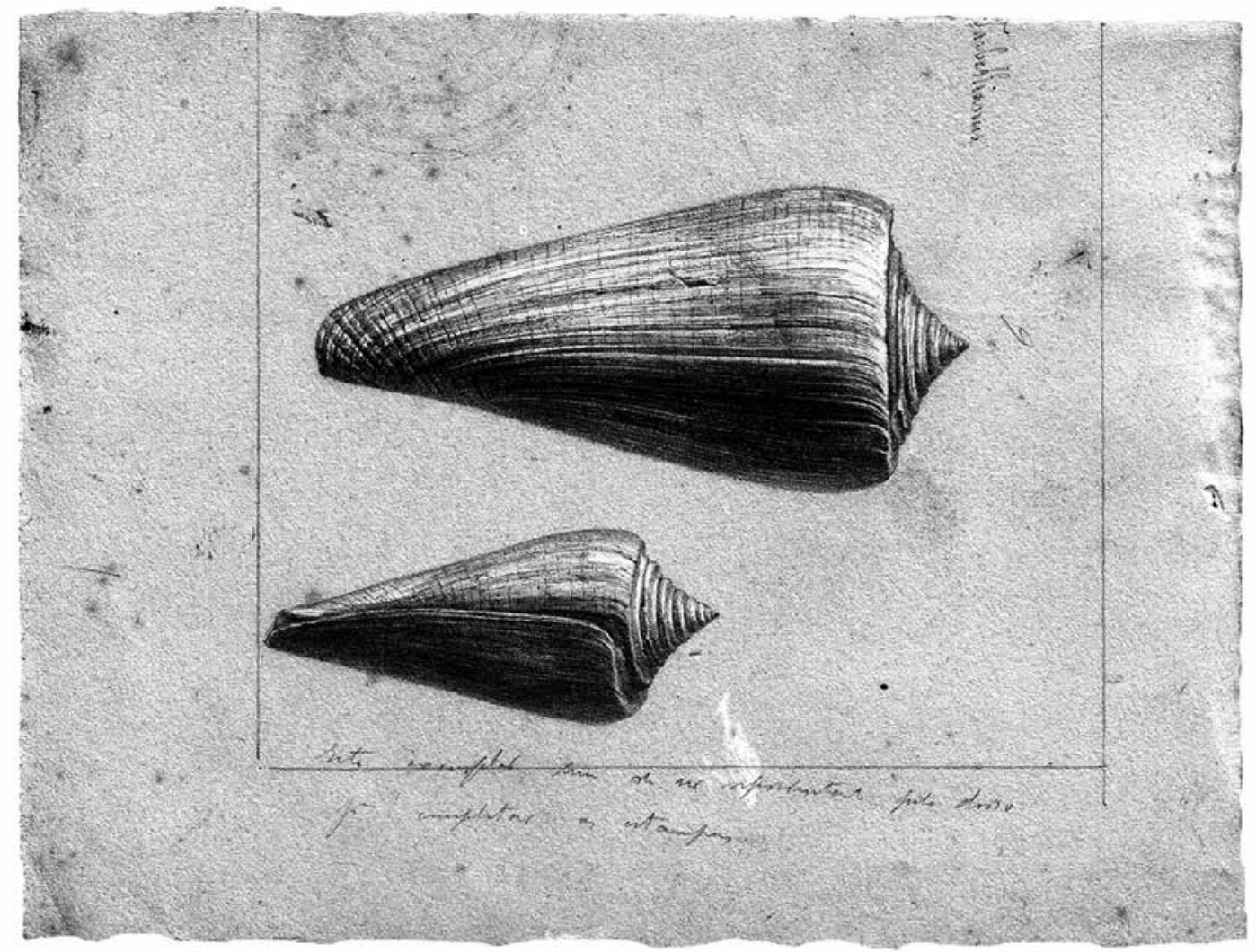

Figura 4: Conus tarbelianus (186-?); lápis sobre papel. Original de Angelino Castro para monografia de Francisco Pereira da Costa (Arquivo Histórico Geológico e Mineiro do Laboratório Nacional de Energia e Geologia, Portugal)

e perda de milhares de exemplares e respectiva documentação, quando do incêndio que em maio de 1978 destruiu parcialmente o edifício da Politécnica.

\section{Considerações finais}

A documentação epistolar disponível, bem como o manuscrito de Carlos Ribeiro com o rol dos fósseis (re)vistos por Paul Deshayes, não deixa dúvidas de que este terá sido, pelo menos na fase inicial de desenvolvimento dos estudos, o grande consultor para o conhecimento da fauna conquiliológica do Terciário português, com as consequentes implicações paleontográficas, estratigráficas e práticas. "A Comissão Geológica [teve] no senhor Deshayes um bom amigo, um prudente conselheiro, um eficaz patrono, e um sábio diretor", dizia Pereira da Costa (Ribeiro, 1859, p.149).

Essa parceria quase invisível, além de adicionar uma 'chancela de qualidade' às determinações feitas pelos membros da Comissão Geológica, demonstra também que eles estavam verdadeiramente atualizados com o que se sabia e de melhor se produzia naqueles domínios do espaço científico europeu, o que se veio a refletir posteriormente no avanço da tão necessária cartografia geológica, peça instrumental e científica determinante para a modernização do Estado português nesse final de século XIX, em termos de afirmação europeia e colonial. 


\section{AGRADECIMENTOS}

A Lydie Touret (École des Mines de Paris) e ao professor Jean Gaudant (Muséum National d'Histoire Naturelle, Paris), pela colaboração prestada na pesquisa de elementos sobre Deshayes, bem como aos professores Fátima Nunes e Margaret Lopes (Universidade de Évora) e Pedro Callapez (Universidade de Coimbra), pela leitura do original e sugestões feitas.

\section{NOTAS}

${ }^{1} \mathrm{O}$ texto deste artigo foi revisado, empregando-se preferencialmente a ortografia usual no Brasil. Nessa e nas demais citações de textos publicados em outros idiomas, a tradução é livre.

${ }^{2}$ Élie de Beaumont (1798-1874), professor e engenheiro de minas, ficou conhecido por sua teoria sobre a formação das cadeias de montanhas e pela participação na elaboração da carta geológica de França de que foi principal autor; Achille Valenciennes (1794-1865), naturalista francês, foi discípulo e continuador de G. Cuvier, tendo produzido trabalhos que relacionavam as faunas extintas com os representantes atuais; Wilhelm von Haidinger (1795-1871), mineralogista e físico austríaco foi conservador das coleções imperiais de mineralogia e diretor do Instituto Geológico em Viena; Joachim Barrande (1799-1883), paleontólogo francês, defensor do catastrofismo, notabilizou-se pelos estudos detalhados da estratigrafia e paleontologia do Silúrico da Boêmia, região a que dedicou longos anos de trabalho; Casiano de Prado (1797-1866), geólogo e engenheiro de minas espanhol, foi um dos pioneiros da Comissão do Mapa Geológico da Espanha; Vilanova y Piera (1821-1893), primeiro catedrático de geologia e paleontologia na Universidade de Madri, foi também membro da Comissão do Mapa Geológico da Espanha.

${ }^{3}$ Essa viagem foi objeto de artigo circunstanciado de Leitão (2001).

${ }^{4}$ Geólogo e mineralogista francês, coautor da carta geológica da França, a que dedicou grande parte do seu trabalho científico.

${ }^{5}$ Esses escritos seriam, anos mais tarde, retomados e acrescentados de novas observações no Traité élémentaire de conchyliologie (1839-1853).

${ }^{6}$ A expressão acéfalos vivos refere-se aos bivalves atuais.

${ }^{7}$ Esse instituto público incorporou o patrimônio dos extintos serviços de geologia nacionais.

${ }^{8}$ Deve-se acrescentar que o estudo detalhado das formações terciárias só viria a ser realizado alguns anos mais tarde pela mão do condutor de minas Jorge Berkeley Cotter (1845-1919), contratado pela Comissão em 1870 para se dedicar, exclusivamente, a esse trabalho.

${ }^{9}$ Sublinhe-se que Deshayes se tinha beneficiado de gesto idêntico por parte de Armand Bazin, detentor de duas importantes coleções consultadas para os Animaux sans vertebres (1860-1866), que também declinara, a favor do primeiro, a descrição das espécies novas identificadas entre seus exemplares.

${ }^{10}$ Lisboa (Rego; Braço de Prata, Forno do Tijolo, Sacavém); Almada (Olho-de-Boi, Boca do Vento, Cacilhas, Margueira; Praia do Covelinho); Sesimbra (Adiça; Foz da Fonte - Espichel).

${ }^{11}$ Pela diversidade e excelência da preservação dos seus exemplares, e pelo facto de constituir a única representação nacional de uma biozona do Miocénico superior em Portugal, a jazida fossilífera de Cacela tem atraído a atenção dos estudiosos, desde meados do século XIX. Os moluscos são os mais representados, não sendo raras as formas de grandes dimensões, sendo também conhecidos, nesta jazida, vestígios de outros grupos paleontológicos, nomeadamente vertebrados, equinodermes e microfósseis. Ver Brandão (2008).

${ }^{12}$ Dada a falta de elementos escritos e as vicissitudes sofridas pelas coleções ao longo do tempo, que passaram por desmembramento e reclassificação, não foi possível apurar se terá sido incorporada a totalidade das peças anunciadas.

13 "Já vimos a coleção de bivalves do Eocênico de Paris. O sr. Costa ficou espantado com a perfeição da maior parte dos exemplares e, nesse meio tempo, encarregou-se de classificar as espécies segundo a listagem da vossa belíssima obra". Carta de Ribeiro (10 fev. 1859) a Deshayes, referindo-se às coleções enviadas por Sæman, muito possivelmente para a Description des coquilles fossiles ou para o Traité de conchyliologie.

${ }^{14}$ Esta carta, assinada primeiro por Costa e em segundo por Ribeiro, foi publicada como introdução ao "Relatório da Comissão Geológica do Reino" no Boletim do Ministério das Obras Públicas, Comércio e Indústria, figurando os autores por ordem inversa. Ver Ribeiro (1859).

${ }^{15}$ Esse pedido, fundamentado na colaboração científica obtida e com o recebimento, a título de oferta à Comissão, de obras e coleções de estudo, incluiu também Haidinger, Hörnes e Casiano de Prado. 
${ }^{16}$ À época, a temperatura era considerada um dos principais condicionamentos das 'forças vitais' e responsável pela distribuição dos seres vivos e por seu desaparecimento no tempo e no espaço.

${ }^{17}$ Deve sublinhar-se que, além das faunas da bacia de Paris, dos Faluns da Touraine e da Aquitânia, Deshayes também conhecia as formas mais quentes do norte de África, com mais afinidades com as portuguesas, que estudara durante sua estada na Argélia no início dos anos 1840. Daí, talvez, tão grande interesse pelas formas portuguesas.

${ }^{18}$ Embora não se refira à proveniência desses fósseis, dada a referência explícita à qualidade de preservação, pode presumir-se que deveriam ser provenientes da jazida de Cacela, da qual Pereira da Costa viria a eleger grande parte das formas com que ilustrou a monografia.

19 "Na coleção que o senhor examinou, tenho algumas dúvidas das quais lhe darei conhecimento assim que me for possível" (Costa, 13 abr. 1860).

${ }^{20}$ Costa referia-se certamente aos trabalhos de Hörnes (1856; 1856-1870).

${ }^{21}$ Jacinto Pedro Gomes (1915-1916), na nota que publicou, refere a existência de coleções de fósseis da bacia de Paris, Bordéus, Dax e Touraine, certamente as vindas do museu da Comissão Geológica. Conclui-se assim que essas ainda mantiveram sua individualidade durante alguns anos, até a definitiva incorporação na Coleção Geral de Paleontologia (exemplares estrangeiros).

\section{REFERÊNCIAS}

BRANDÃO, José M.

Peças de Adolphe d'Archiac no núcleo inicial de colecções estrangeiras da Comissão Geológica de Portugal. In: Brandão, José M. et al. (Ed.). Colecções e museus de geologia: missão e gestão. Coimbra: Museu Mineralógico da Universidade de Coimbra; Centro Estudos História e Filosofia da Ciência. p.139-145. 2010.

BRANDÃO, José M.

Uma colecção centenária de fósseis de Cacela: um património museológico com relevância científica e histórica. Centro de Interpretação do Patrimônio de Cacela. Disponível em: http://repositorio.lneg.pt/handle/10400.9/422. Acesso em: 20 fev. 2011. 2008.

BRANDÃO, José M.; ALMEIDA, Joanna. O conhecimento da "rica fauna terciária neogénica": uma efeméride na história das geociências portuguesas. In: Seminário de Paleontologia e Arqueologia do Estuário do Tejo, 1., Actas... Lisboa: Colibri; Câmara Municipal de Montijo. p.99-110. 2005.

COSTA, Francisco Pereira da.

Molluscos fosseis: gasterópodes dos depósitos terciários de Portugal. Lisboa: Comissão do Serviço Geológico. 1866-1867.

COSTA, Francisco Pereira da.

[Carta a Deshayes]. Documento avulso.

LNEGCG.13.04.162. (Arquivo Histórico

Geológico e Mineiro do Laboratório Nacional de Energia e Geologia, Alfragide). 13 abr. 1860.

COSTA, Francisco Pereira da.

[Ofício a Filipe Folque]. Livro de registo

de correspondência expedida. p.26.

LNEGCG.13.02.69. (Arquivo Histórico Geológico e Mineiro do Laboratório Nacional de Energia e Geologia, Alfragide). 1 dez. 1859.

COSTA, Francisco Pereira da.

[Carta a Casiano de Prado]. Livro de correspondência expedida. p.16-17.

LNEGCG.13.02.69. (Arquivo Histórico Geológico e Mineiro do Laboratório Nacional de Energia e Geologia, Alfragide). 16 abr. 1859.

COSTA, Francisco Pereira da.

[Carta a Filipe Folque]. LNEGCG.04.21. (Arquivo Histórico Geológico e Mineiro do Laboratório Nacional de Energia e Geologia, Alfragide). [1859].

COSTA, Francisco Pereira da; RIBEIRO, Carlos. [Carta a Filipe Folque]. Livro de registo da correspondência expedida. p.18.

LNEGCG.13.02.69. (Arquivo Histórico Geológico e Mineiro do Laboratório Nacional de Energia e Geologia, Alfragide). out. [1859?].

CROSSE, Hippolyte; FISCHER, Paul Henri. Nécrologie: Gérard Paul Deshayes. Journal de conchyliologie, Paris, v.16, n.1, p.123-127. 1876.

DESHAYES, Gérard Paul.

[Dons faits a la Société: communication de M. Deshayes sur l'œuvre de Pereira da Costa, Gasteropodes dos depositos terciarios de Portugal, 1866]. Bulletin de la Société Géologique de France, Paris, v.24, n.2, p.168-170. 1867.

DESHAYES, Gérard Paul.

Description des animaux sans vertèbres découverts dans le bassin de Paris. 3v., 2 atlas. Paris: J.-B. Baillière. 1860-1866.

DESHAYES, Gérard Paul.

[Carta a Carlos Ribeiro]. LNEGCG.02.03.131. 
(Arquivo Histórico Geológico e Mineiro do Laboratório Nacional de Energia e Geologia, Alfragide). 31 maio 1863.

DESHAYES, Gérard Paul.

[Carta a Carlos Ribeiro]. LNEGCG.02.03.131. (Arquivo Histórico Geológico e Mineiro do Laboratório Nacional de Energia e Geologia, Alfragide). 27 out. 1859.

DESHAYES, Gérard Paul.

Traité élémentaire de conchyliologie: avec les applications de cette science à la géologie. 3v.,1 atlas. Paris: Crochard. 1839-1853.

DESHAYES, Gérard Paul.

Description des coquilles fossiles des environs de Paris. 2v., 1 atlas. Paris: L'auteur, chez Bechet jeune. 1824-1837.

DESHAYES, Gérard Paul.

Description des coquilles caractéristiques des terrains. Paris: Levrault. 1831.

DOLLFUS, Gustave; COTTER, Berkeley; GOMES, Jacinto Pedro.

Mollusques du tertiaire du Portugal: planches de Céphalópodes, Gastéropodes et Pélécypodes laissées par F.A. Pereira da Costa, acompagnées d'une explication sommaire et d'une esquisse géologique. Lisboa: Commissão do Serviço Geologico de Portugal. 1903-1904.

EVANS, John.

Obituary: Gérard Paul Deshayes. The Quaterly Journal of the Geological Society of London, London, v.32, p.80-82. 1876.

GOMES, Jacinto Pedro.

Notas sobre a disposição das colecções da secção Mineralógica e Geológica do Museu Nacional. Comunicações dos Serviços Geológicos de Portugal, Lisboa, v.11, p.138-144. 1915-1916.

HÖRNES, Moriz.

Die fossilien Mollusken der tertiaer-Beckens von Wien. Wien: K. K. Hof-und Staatsdruckerei. 1856-1870.

HÖRNES, Moriz.

Verzeichnis der im Wiener Becken vorkommenden Gastropoden und Pteropoden mit Angabe der Fundorte in und ausserhalb desselben. Wien: s.n. 1856.
LEITÃO, Vanda.

The travel of geologist Carlos Ribeiro (18131882 ) to Europe, in 1858. Comunicações do Instituto Geológico e Mineiro, Lisboa, v.88, p.293-300. 2001.

LYELL, Charles.

Manuel de géologie élémentaire, ou, Changements anciens de la terre et de ses habitants tels qu'ils sont représentés par les monuments géologiques. $5^{\mathrm{ème}}$ ed. Paris: Langlois et Leclercq. 1856.

RIBEIRO, Carlos.

Des formations tertiaires du Portugal. Congrés International de Géologie, Paris, 1878. Compte Rendu... Paris: Imprimerie Nationale. 1880.

RIBEIRO, Carlos.

[Carta a J.-B. Baillière]. Livro de correspondência expedida. p.9. LNEGCG.13.02.86. (Arquivo Histórico Geológico e Mineiro do Laboratório Nacional de Energia e Geologia, Alfragide). 8 mar. 1859.

RIBEIRO, Carlos.

[Carta de agradecimento a Deshayes, no regresso da viagem feita pela Europa]. LNEGCG.02.04.95. (Arquivo Histórico Geológico e Mineiro do Laboratório Nacional de Energia e Geologia, Alfragide). 10 fev. 1859.

RIBEIRO, Carlos.

Relatório da Comissão Geológica do Reino. Boletim do Ministério das Obras Públicas, Comércio e Indústria, Lisboa, n.2, p.148-166. 1859.

RIBEIRO, Carlos; COSTA, Francisco Pereira da. Indicazioni relative alla Comizione di Geologia nel Portogallo. Atti della Societá Italiana di Scienze Naturali, Milano, v.8. (Separata). 1865.

SHARPE, Daniel.

On the geology of the neighbourhood of Lisbon. Transactions of the Geological Society of London, London, series 2, v.6, p.107-133. 1841.

SMITH, James.

On the age of Tertiary beds of the Tagus, with a Catalogue of the fossils. Quarterly Journal of the Geological Society of London, London, v.3, p.410-423. Jan. 1847.

ZITTEL, Karl Alfred von.

History of geology and paloeontology to the end of the nineteenth century. London: W. Scott. 1901.

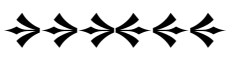

